\title{
The Impact of The Development of Blended Learning Models Using Computer applications in Higher Education
}

\author{
Munir Tubagus ${ }^{1}$, Suyitno Muslim ${ }^{2}$, Suriani $^{3}$
}

\section{ARTICLE INFO}

Article History:

Received 15.03.2019

Received in revised form

12.06.2019

Accepted

Available online 01.10.2019

\begin{abstract}
This study showed that the impact of development of blended learning models can improve student learning outcomes, the learning process that utilizes information technology in the form of computers which equipped with telecommunications facilities (Internet, intranet, and multimedia (graphics, audio, video) as a medium in the delivery of materials and interactions between teachers and learners. This method of research was R\&D (Research and Development), which research was to produce products and test the effectiveness of the product. There were four phases of e-learning making, including (1) system analysis including hardware, software, learning and student development materials (2) designing, including instructional design analysis, teaching materials and media (software) (3) Implementation, namely the product and development of the resulting Learning Management System, (4) evaluation, which was the assessment stage by experts to test the feasibility of the System. This research was conducted at the Institute of Islamic Religion (IAIN) Manado Faculty of Economics and Islamic Business. Data collection techniques were conducted in three ways, namely (1) observation, (2) document analysis, and (3) interviews. The data validity technique in this study was the triangulation technique.
\end{abstract}

(C) IJERE. All rights reserved

Keywords: ${ }^{1}$

Model Development, blended learning, communication media, computer applications.

\section{INTRODUCTION}

Integration of Information, Communication, and Technology (ICT) in education refers to the use of computerbased communication that incorporates into daily classroom instructional process. In conjunction with preparing students for the current digital era, teachers are seen as the key players in using ICT in their daily classrooms. This is due to the capability of ICT in providing dynamic and proactive teaching-learning environment (Hatlevik \& Arnseth, 2012). The use of ICT in education has intensely reformed learning and teaching processes. Furthermore, it has expanded new opportunities for learning and accessing to educational resources beyond those traditionally available (Talebian, Mohammadi, \& Rezvanfar, 2014). In traditional learning or conventional class, teacher is the center of learning process and the students are mostly passive learners. Therefore, the teacher only taught what was is inside the book and the students inquired to listen to the lesson and pay attention with almost negligible participation in the class but for the expansion of the technology now the students can get many sources and information they want easily (Mohammed, Wakil, \& Nawroly, 2018).

\footnotetext{
Corresponding e-mail: Corresponding e-mail: matrix.bagus@gmail.com, orcid.org/0000-0003-2266-2665;

1 Student, Department of Education Technology, Jakarta State University, Jakarta, Indonesia

2 orcid.org/0000-0001-9313-1592; ${ }^{3}$ orcid.org/0000-0001-5184-7410

2,3 Lecturer, Department of Education Technology, Jakarta State University, Jakarta, Indonesia
} 
E-Learning concept applied in higher education institutions with blended learning model is a means of communication in learning. While many of the definitions of blended learning include the application of in-face learning in class with the long-distance construction (Garrison \& Vaughan, 2008). Blended Learning spreads as a form of learning and teaching approach that combines face-to-face learning and online learning, or elearning with a synchronous and asynchronous step-by-step work. This learning aims to complement each other and enhancing the learning experience as the whole (Track Dinning, 2005). Blended learning is an effective combination of face-to-face and longdistance learning in higher education in both lectures and seminars. In general, e-learning learning process can be an independent online learning system, or also combined with a direct-face learning process in a class that relies on attendance (instructor dependent). (Tolks et al., 2014)

Described the relationship between distance learning, networked learning and web-based learning." These learning models can be done in a variety of situations and conditions that are not limited by time (Dabbagh, 2005). Another opinion expressed by (Macdonald, 2008) states that "I intend to develop a more detailed description of the characteristics of blended learning later in this book, but I should point out that there has already been much useful and relevant work in the field, from people who have not used the term blended learning, and yet refer to the same or very similar concepts. For example, papers on online or networked learning very often refer incidentally to the use of synchronous face-to-face or telephone tuition sessions, alongside the use of online asynchronous learning". A more detailed explanation of the characteristics of blended learning in this book shows that the development of the use of blended learning is very relevant to the student work. As an example of a paper in the course of applying synchronous-face learning in class with the learning of Asychronus using online networking.

The results of learning process are the actual ability that can be measured directly, where the results of the study measurement will be known how far the education and teaching objectives have been achieved. Learning outcomes play a very important role in the learning process. The Learning assessment process can provide teachers with information about the progress of students in achieving their learning objectives through study, and then teachers can then arrange and plan the process of further learning as an effort to achieve better learning objectives. Some research results show that learning effectiveness with blended learning models is better compared to traditional or conventional learning. The results of the study of (Khlaisang \& Likhitdamrongkiat, 2015) to answer questions on the basis of the importance of using educational technology by developing an e-learning system to improve students ' cognitive skills in Higher education. It demonstrates that there was increase and progress of students' cognitive skills. Further research conducted by (Kintu \& Zhu, 2016) found that the learning influence of blended learning towards learning results showed significant results. This shows the learning of blended learning results of student learning. Research was conducted by blended learning as a means to implement an effective open learning model of the traditional to integrated learning model where the environment and electronic resources are widely used. Research by (Ali, Joyes, \& Ellison, 2014) ) introduces a new 
method on how to measure online learning and face-to-face activities in a mixed concept in colleges, to promote the use of e-learning among lecturers and students in developing collaborative work skills as an effective team. The results are excellent as well as each group works as a team both online and face-to-face in completing their task.

Referring to existing research results, blended learning models that combine face-toface learning with online learning shows the ability to improve students ' understanding of learning materials can improve students' learning achievements. It is necessary to do research that can develop strategies or learning models that become alternatives to achieve effective learning objectives. The potential application of learning with the blended learning system is very possible to implement, along with the development of information technology. The applied blended learning Model is presented and evaluation of students who take the programming course conducted. Therefore, the student adaptation period in mixed education is shortened. Our results suggest that the algorithmic thinking skills of students enrolled in algorithm and programming courses in mixed and traditional education are very close.

\section{Situation of the Problem}

This research is to solve problems that occur in learning by developing e-learning model with the concept of blended learning models in higher education, can be formulated as follows:

a) To get a general overview of the conceptual model of the development of blended learning in higher education.

b) To develop a learning procedural model based on blended learning in higher education

c) To evaluate that blended learning is an effective learning model that can be applied to higher education.

\section{Aim of the Study}

The purpose of the Blended Learning development model is firstly, it helps students to develop better in the learning process, according to the learning style and preference in learning. Secondly, it provides a realistic practical opportunity for lecturers and students to study independently, rewarding, and evolving. Thirdly, it improves the flexibility of scheduling for students by combining the best aspects of face-to-face and online instructions. Face-to-face classes can be used to engage students in an interactive experience. While the online portion provides students with rich multimedia content all the time and anywhere during the students have internet access. Fourth, it overcomes learning problems that require completion through the use of varied learning methods.

\section{METHOD}

The approach in this study used mixed methods research, a procedure to collect, to analyze, and to incorporate quantitative and criminal methods in a study or series of studies to understand the problem research. The basic assumption of the combination 
usage of quantitative and qualitative methods gives a better understanding of the issue of the research question rather than using only one method (Creswe, 2015). The problem in this study is how to develop a blended learning model that combines face-to-face learning with online learning in the course of management information systems.

Broadly, the stage of learning model e-learning based on blended learning research refers to the model of research and development of (Gall, 2007), which includes the following 10 steps: (1) Research and data collection (research and collecting information), (2) planning, (3) Development of drafts (develop, preliminary form of product), (4) Initial field trials (main product revision), (5) Revise the results of the trial (main product revision), (6) Field trials (main field testing), (8) Enhancement of field test products (Operational product revision), (8) field exercise test (operational field testing), (9) Completion of final product revision, and (10) dissemination and implementation. This model was developed and evaluated by experts and students. There were six experts involved in evaluating this model. This research was conducted at the Manado State Islamic Institute (IAIN) in 2018. In its execution, the research and development measured of the Gall were grouped into 4 stages, namely (1) the introductory phase, (2) Planning and Development, (3) evaluation and revision, and (4) implementation. In the second step, especially at the development stage refers to the model of learning system development (Walter Dick, 2015).

\section{a) Preliminary Investigation}

This section consists of conceptual studies and field studies aims to examine the results of previous studies relating to the validity of the components to be developed. These first steps include need analysis, library study, literature study, small-scale research and required report standards. To perform the need analysis there were several criteria related to the urgency of product development and product development itself, also the availability of competent human resources and adequacy of time to develop the research. The literature study was conducted for a temporary introduction to the product to be developed, and it was conducted to collect research findings and other information concerned with the development of the planned product. While small-scale research needs to be conducted for the researcher to know some things about the product.

b) Analysis

Analysis steps; (1) Validate performance gaps: Measure actual performance, assign performance that want to be achieved, identify the cause; (2) Formulating instructional objectives: Using Bloom's taxonomy and other taxonomy; (3) Identifying student Characteristics: ability, experience, motivation, attitude and others; (4) Analyzing technology resources and availability.

c) Design

Design was the stage after the analysis process where this stage was the advanced or core activity of the analysis step. The learning design was also said to be designed in the learning process. The design was compiled by studying the problems, then looking for solutions through identification of the analysis stage needs in the previous process. One of the objectives of this phase was to determine the appropriate learning strategy so that students can achieve their objectives in the educational process, especially in achieving the 
competency standards that have been determined in the learning process. The goal of this stage was to verify the performance to be achieved and the appropriate test method selection. The general steps pursued in learning were: (1) compiling a list of tasks; (2) Develop performance objectives; (3) Develop a test strategy; (4) calculating the investments/costs incurred. The design components used were task arrangement diagrams, complementary devices about learning objectives, complete test devices, test strategies, investment proposals/fees incurred.

d) Development process

This section consists of three components:

1) Develop a learning assessment tool

2) Develop collaborative learning strategies

a) Engagement. At this stage, teachers perform assessments of the individual students ' abilities, interests, talents and intelligence. Then, students were grouped in which there were the smartest students, moderate students, and students who were low in their achievements.

b) Exploration. After grouping, then teachers started to give assignments, for example by giving problems to be solved by the group. With the problems acquired, all members of the group must strive to share their skills in the form of knowledge, opinions or ideas.

c) Transformation. From the different abilities which each student has and each member was exchanging thoughts and conducting group discussions. That way, students who initially have low achievements, will be able to raise their achievements because of the transformation process of students who have high achievement to the students whose achievements were low.

d) Presentation. After completing the discussion and compiling the report, each group presented the results. When one of the groups was presenting, the other group observed, noticed, compared the results of the presentation, and responded.

e) Reflection. After completing the presentation, the FAQ process occurred between groups. The group that performed in the presentation received questions, responded or disclaimed from other groups. With questions posed by other groups, group members must cooperate in a compact order to respond well.

3) Develop learning materials

The purpose of this stage was to produce and validate learning resources through (1) content creation; (2) Selecting and forming supportive media; (3) Establishing a guide for students; (4) forming guidance for lecturers; (5) Prepare for formative revisions; (5) Form pilot tests or preliminary tests and hold them.

e) Implementation

A learning plan that has been created would not be known by the outcome if there is no action. The action was very meaningful because the learning will bring about the new impact that can be made experience or even reference when there was the result. This was 
a necessary implementation that means implementation or the application of a plan in which it is one of Gell models that became a unity with the previous stages as a refinement and quite influential in the implementation of the learning.

The implementation or delivery of learning materials was the fourth step of Gell's learning system Design model. The main purpose of this step was (1) guiding students to achieve goals or competencies; (2) Ensuring problem solving/solution to overcome the gap of learning outcomes faced by the learning. (3) Ensuring that at the end of the learning program, learning needs to have the competence of knowledge, skills, and attitudes required.

f) Evaluation

The prepared learning planning will pass through the stages of the Gell model development smoothly and end at a stage called evaluation. Evaluation was the stage in which the action was aimed to determine the success of a learning plan, the things have done for the success of this stage was not merely intact at this stage alone but the evaluation can also occur in the previous stages. In the implementation of the evaluation should take into account the objectives that were to be achieved at the beginning of the planning because an evaluation or assessment has the criteria to know its achievement to the specified limit or not and from such activities required the information and data needed from the objects to be evaluated in order to smooth the evaluation process.

The goal of the evaluation phase was to measure the quality of products and processes before and after the implementation of activities. The main procedure of the evaluation process was: (1) specifying the evaluation criteria; (2) Choosing a tool for evaluation; (3) Conducting evaluation itself. The result of the evaluation was evaluation planning. The components of the evaluation planning were: an overview of the purpose, the data collector tool, responsibility for time and individual/group for each level of evaluation; A set of evaluation assessment criteria; A set of tools for evaluation.

\section{Material}

The data in this study includes data analysis, class observation results was conducted by researchers for 6 months at the Institute of Islamic Studies (IAIN) Manado Faculty of Economics and Islamic Business. In addition to observation data, researchers also used the interviews to the lecturers and students at faculty. Subsequently this model was developed and evaluated by experts and students. Six experts were involved to evaluate this model. Model trials were carried out by lecturers and students after the model revision was completed. How to Improve Students' Computer Skills? Online Learning in Higher Education to Encourage Critical Thinking Skills in the 21st Century. (Wardani, Martono, Pratomo, Rusydi, \& Kusuma, 2018).

\section{Data Analyses}

The analytical techniques in this study used interactive analysis techniques. Interactive model analysis is component interaction, i.e. data collection, data presentation, data reduction, and conclusion withdrawal. 


\section{FINDINGS}

The findings of this research can be used to recommend effective learning and teaching using e-learning, so that it can improve student learning outcomes in higher education. The implications of this research recommendation were to encourage them to use e-learning technology and facilitate students in improving learning outcomes as well as academic experiences in accordance with the context and educational objectives Intended. The study also found that the right innovation of learning will generate selfreliance as well as confident students who have sought to find and explore learning resources not only from teachers. This assumption leads to implement blended learning becomes an option when learning was not enough only by face to face. Students get the opportunity to develop communication skills both in class and out of class through online interaction with each other while discussing the problem together. For teachers, it can optimize the learning model in the improvement learning of students in particular management information system. Unique learning in accordance with the context and purpose of the education intended.

\section{RESULT, DISCUSSION AND SUGGESTIONS}

Based on findings, research proved that the model of the development of blended learning in higher education contributes positively to student learning outcomes. These findings reinforced the research which was conducted by (Hubackova \& Semradova, 2016) showed that blended learning is not only acceptable but highly liked by students. Students receive new technology quickly and learn easily. Blended learning is a combination of online-face learning using the principle of constructivism which was suitable and necessary even for the teaching of foreign languages. The results of the study answered questions about the basic and important use of educational technology by developing an e-learning system at BLE to improve cognitive skills for students in higher education. In addition this model integrates educational technology and pedagogy to improve cognitive skills for learners in higher education that will lead to applications in higher education (Khlaisang \& Likhitdamrongkiat, 2015).

This study investigated students' perception about the effectiveness and efficiency of blended learning models in teaching and learning. It used case studies design and 120 business school students were enrolled in private universities that were being investigated. The results showed that the use of online discussion tools between students and lecturers need to be improved in the blended learning environment. Computer systems need to be upgraded in the future so that all online materials will be accessible to students. In addition, lecturers need to use more online courses, online exercises in teaching. In general, results show significant in the use of blended learning models in learning and teaching. The use of blended learning will not only enhance college learning experience, students but also provides a quality and overall friendly learning environment (Wai \& Seng, 2014). Blended Learning programs provide a viable solution for trainees for ongoing education, combining a type of classic learning with online learning(Catalano, 
2014). Blended learning is a potential result of a learning system based on advanced technology, blended learning, can shift rigid traditional education system towards a more flexible, interactive, easily accessible network structure in both teachers and students. It can generally be applied and can serve as a basis for further research that leads to the creation of a viable cross-university system that is suitable for higher education (Khan, Shaik, Ali, \& Bebi, 2012).

Based on the assumptions above, blended learning-based learning is the best choice to increase effectiveness, efficiency, and greater attractiveness in interacting between people in a diverse learning environment. Blended Learning offers the opportunity to learn together and separately, as well as at the same time and in different times. A learning communication can be done by students and teachers who can interact at any time and on the go because it utilizes the use of a computer or other devices (iPhone) as a learning facility. Blended Learning has a number of advantages compared to traditional learning courses. One of the advantages of blended learning is that it is easily adapted to the needs of learners. Adaptation comes from a variety of ways how online resources can be used. The most important component of blended learning is its flexible program. If the teacher notices the problem that a student has on learning the course, he or she can quickly solve this problem by changing the material and learning activities. The needs of individual learners should be considered, if not, even a well-designed course can fail. If the course is flexible, it contributes to increase the motivation of learners.

\section{CONCLUSION}

The research and development process has produced a blended learning product in the management information systems course. The product consisted of a procedural model and a physical model. The procedural Model was the construction result of a theoretical study manifested in the form of an image. A successfully developed procedural model consists of measures to develop a blended learning model in the management Information systems course. While physical products are realized in the form of a program (System) for blended learning based on learning Management Systems (LMS) equipped with learning tools such as lesson plans, teaching materials compilation, and evaluation system.

With blended learning students can learning independently, tested learning material, use multimedia learning, can be accessed online anytime, learning more effectively and on target. It can be applied to higher education. This assumption became a guideline to choose blended learning to be an option when learning is not enough only by face to face method. Students have the opportunity to develop communication skills both in class and outside of class through online interactions with each other discussing common issues, so teachers can optimize learning models in improving self-reliance learning students. Before the process of implementing blended learning models should make careful planning such as the purpose of e-learning use, equitable equality of the use of media e-learning, efficiency and effectiveness of e-learning. This research has only been tested at the level of higher education at the Institute of Islamic Studies (IAIN) Manado, however blended learning models are suitable for use in each group but it should pay attention to some 
aspects before the implementation process is done. For instance, readiness of students and availability of supporting sources such as internet networks. The blended learning model is used to have a positive influence on the improvement of technology' users, therefore, it can be used as the basis for other researches with different case studies.

\section{REFERENCES}

Ali, M. F., Joyes, G., \& Ellison, L. (2014). Building effective small-group team working skill through blended learning at Malaysia Tertiary Institution. Procedia-Social and Behavioral Sciences, 112, 997-1009.

Catalano, H. (2014). The opportunity of blended-learning training programs in adult education-Ascertaining study. Procedia-Social and Behavioral Sciences, 142, 762-768.

Creswe, J. W. (2015). Educational research : planning, conducting, and evaluating quantitative and qualitative research (Vol. Fourth Edition ): USA: Prentice Hall.

Dabbagh, N. (2005). Bannan-retland brenda, online learning: Concept, strategies, and application (Vol. First): New Jersey: Pearson Education Inc.,.

Gall, M. D., Gall, J. P., \& Borg, W. R. . (2007). Educational research (Vol. Eighth Edition): Boston: Pearson.

Garrison, D. R., \& Vaughan, N. D. (2008). Blended learning in higher education: Framework, principles, and guidelines: John Wiley \& Sons.

Hatlevik, O., \& Arnseth, H. (2012). ICT, Teaching and Leadership: How do Teachers Experience the Importance of ICT-Supportive School Leaders? (Vol. 2012).

Hubackova, S., \& Semradova, I. (2016). Evaluation of blended learning. Procedia-Social and Behavioral Sciences, 217, 551-557.

Khan, A. I., Shaik, M. S., Ali, A. M., \& Bebi, C. V. (2012). Study of blended learning process in education context. International Journal of Modern Education and Computer Science, 4(9), 23.

Khlaisang, J., \& Likhitdamrongkiat, M. (2015). E-learning system in blended learning environment to enhance cognitive skills for learners in higher education. Procedia-Social and Behavioral Sciences, 174, 759-767.

Kintu, M. J., \& Zhu, C. (2016). Student characteristics and learning outcomes in a blended learning environment intervention in a ugandan university. Electronic Journal of e-Learning, 14(3), 181-195.

Macdonald, J. (2008). Blended learning and online tutoring. Planning learner support and activity design (Vol. First): Gower Publishing Company

Mohammed, G. S., Wakil, K., \& Nawroly, S. S. (2018). The effectiveness of microlearning to improve students' learning ability. International Journal of Educational Research Review, 3(3), 32-38.

Talebian, S., Mohammadi, H. M., \& Rezvanfar, A. (2014). Information and communication technology (ICT) in higher education: advantages, disadvantages, conveniences and limitations of applying e-learning to agricultural students in Iran. Procedia-Social and Behavioral Sciences, 152, 300-305.

Tolks, D., Pelczar, I., Bauer, D., Brendel, T., Görlitz, A., Küfner, J., . . Hege, I. (2014). Implementation of a blended-learning course as part of faculty development. Creative Education, 5(11), 948.

Track Dinning, C. M., Julie Money, Barbara Walsh, Sarah Nixon (2005). Can blended learning approach enhance students transition into higher education a study to explore perceptions, engagement and progression. International Journal of Advancement in Education and Social Sciences, Vol.3, No. 2, 1-7 7.

Wai, C. C., \& Seng, E. L. K. (2014). Exploring the effectiveness and efficiency of blended learning tools in a school of business. Procedia-Social and Behavioral Sciences, 123, 470-476.

Walter Dick, L. C., James O. Carey (2015). The systematic design of instruction (Eighth Edition ed.): Pearson.

Wardani, D. K., Martono, T., Pratomo, L. C., Rusydi, D. S., \& Kusuma, D. H. (2018). Online learning in higher education to encourage critical thinking skills in the 21st century. International Journal of Educational Research Review, 4(2), 146-153. 